\title{
Е.М. МИХАЙЛОВА
}

\section{НАЦИОНАЛЬНЫЙ ВОПРОС В ПОЛИТИЧЕСКОЙ ИДЕОЛОГИИ ПРАВОГО КОНСЕРВАТИЗМА: ИМПЕРСКИЙ И РЕГИОНАЛЬНЫЙ ДИСКУРС}

\begin{abstract}
Ключевые слова: национальный вопрос, правые партии, правый консерватизм, имперская модель, Поволжье, начало XX в.

В статье анализируются взгляды правоконсервативных партий и организаций начала XX в. на национальный вопрос. Рассмотрены позиции правых по отношению к русскому народу, нерусским народностям внутренней России и народностям национальных окраин, выделены фракторы подобной дифрференциации. Особое внимание обращено на продиктованные многонациональным и поликонфессиональным составом региона особенности национальной политики правоконсервативных партий и организаций Поволжья начала XX в. Автором выделены схожие с общероссийскими правыми партиями позиции у поволжских консерваторов, в частности в отстаивании принципа единства и неделимости Российской империи, недопущения расчленения страны. Определены отличительные черты национальной проблематики у правомонархических партий Поволжья, выразившиеся во включении в их программные платформы положений о предоставлении равных с русскими гражданских прав инородцам, о допуске свободного вероисповедания инославным, об использовании национальных языков параллельно с государственным русским языком. Отмечены фракторы радикализации у правых консерваторов национальной тематики в условиях Первой мировой войны.
\end{abstract}

Первая русская революция 1905-1907 гг. обнажила политические противоречия и проблемы российской действительности. Возникшие на фоне активизации общественно-политической жизни политические партии и организации предлагали свои решения по актуальным для Российской империи начала XX в. вопросам, в том числе по национальному, обострившемуся в контексте революционных событий, проблеме роста национального самосознания и формирования национальных движений на окраинах страны.

Правые партии и организации, оформившиеся на контрреволюционной волне, предложили свое видение национальной проблематики, выраженное в консервативной парадигме. Стратегической концепцией решения этого вопроса правыми виделось сохранение единства и неделимости страны. В «Основоположениях» Союза русского народа (CPH) отмечалось, что он (CPH. - E.M.) «твердо объявляет и всенародно исповедует неделимость и целостность Российской империи в ее теперешних границах и постановляет своим священным и непреложным долгом всеми силами содействовать тому, чтобы завоеванные кровью предков земли навсегда остались неотъемлемой частью Русского государства» [21]. В избирательной платфрорме, принятой в сентябре 1906 г. I Всероссийским съездом уполномоченных отделов СРН в рамках избирательной компании во II Государственную Думу, подчеркивалось, что «все попытки к расчленению России, под каким бы то ни было видом, решительно и безуслов- 
но были устраняемы» [14. Т.1. С. 191]. Та же позиция была выражена в начале 1907 г. в совместном обращении СРН, Русского собрания и Партии правового порядка: «Мы будем стремиться к тому, чтобы великая Россия оставалась всегда единою и нераздельною» [16. С. 73].

Единство и неделимость страны рассматривались практически всеми правыми партиями как «безусловная политическая ценность». Парадигмальной моделью воплощения принципа единства страны для правых выступала имперская модель. Только в подобном фрормате были возможны максимальное выражение национального интереса государства и защита ценностных принципов российского народа. Такая модель, по мнению правых, объединяла народности Русского государства в соборном единстве, гарантировала их независимость от внешних врагов.

Исходя из имперской модели национально-территориального устройства государства правые выступали против автономных образований и против самоопределения национальных окраин России. Их создание могло привести к расчленению страны, что было для консерваторов совершенно недопустимым. Имперская система унитарного государства в воззрениях правых не допускала и фредерализации. В обращении Союза русского народа, подготовленном в июле 1907 г., говорилось: «Россия единая, неделимая, без тени каких бы то ни было автономий для окраин» [20].

В национальной проблематике правые различали русский народ, коренное нерусское население исконной части России, к которым причислялись населяющие Поволжье народы, нерусские народности окраинной части России. Эта дифференциация дополнялась на местах соответствующей специфрикой, продиктованной региональным контекстом.

Важнейшими причинами такого разделения в национальном вопросе для правых выступали фрактор вовлеченности национальных меньшинств в общую жизненную канву страны, соответствие их жизнедеятельности общероссийским национальным интересам. К дружественным относились народы, сумевшие преодолеть узконациональные интересы, ставящие благо России на первое место, принимавшие базовые принципы русского культурноисторического сообщества, «выросшие до понимания общеимперских интересов и своей роли во внутригосударственном разделении обязанностей» [15. С. 245]. Особое значение в национальной диффреренциации имел революционный фрактор. Участие в революционном движении и сепаратистских выступлениях представителей национальных меньшинств давали правым явный повод обвинять эти силы (а вину распространить и на народ) в попытке расчленить Россию и разрушить ее коренные, традиционные устои, что абсолютно противоречило доктринальным принципам правоконсерваторов.

Русский народ в доктрине правых консерваторов рассматривался «государствообразующей» нацией, собравшей русские земли, скрепляющей все народности, входящие в российское государство. Он же выступал гарантом целостности империи. Русской национальности, создавшей Русское государство и несшей основные государственные повинности, должна была принадлежать «первенствующая роль в государственном строительстве». Такой точки зрения придерживались практически все правомонархические партии. Доминирующее положение русского народа предполагалось закрепить различными средствами политико-экономического характера. Особенно это касалось усиления русского влияния на национальных окраинах. 
К коренному нерусскому населению относились те народности, которые вошли в состав Российского государства со своей «исконной» территорией. Что касается окраин России, здесь дело обстояло острее. В частности, возникновение украинского, польского, фринляндского вопросов правые рассматривали как «опасность для единой и неделимой России» [17. С. 309]. Отдельно рассматривался еврейский вопрос, в котором все правомонархические партии, от столичного до регионального уровня, были схожи в своих позициях и исходили из ограничения прав евреев во всех сферах общественной жизни.

Однако говорить о националистической парадигме в решении национального вопроса правыми было бы крайне неверно. Для правых понятия «русский народ» и «Российское государство» рассматривались как синонимы. Защита правыми интересов русского народа как национальности понималась ими как защита интересов всех народов, входящих в Российскую империю. В содержание лозунга «Россия для русских», прозвучавшего в программных положениях ряда правых партий, вкладывалось в целом широкое значение. В понятие «русский народ» включались все «верноподданные» народности, живущие общенациональными российскими интересами [7. С. 59-81].

Национально-государственная проблематика получила значительное внимание и во взглядах правых партий, созданных на местах, в том числе в Поволжье. По основным положениям национальный вопрос в воззрениях поволжских правых партий совпадал с позициями общероссийских правых. Это касалось, прежде всего, принципа сохранения единства и неделимости страны. Наиболее известная в регионе Астраханская народно-монархическая партия (АНМП) основной целью своей программы определяла требование «не допустить Россию до распадения» (что было отражено в первой статье программы партии) [5. Л. 1]. Ей вторило Общество церковных старост и приходских попечителей (ОЦСПП), созданное в Казани. Третий раздел его программы, который назывался «Отечество», определял следующий принцип национальной политики: «Первое и основное благо России в ее целости и неделимости» [18. Л. 5].

Как и столичные правые партии, поволжские консерваторы выступали против автономных образований и федеративного устройства в российской политической системе. Они сходились со столичными традиционалистами в оценке роли русского народа в создании и расширении Российского государства. «Русскому племени, - отмечалось в программе ОЦСПП, - вынесшему на своих плечах всю тяжесть создания и объединении Русского государства, должна принадлежать главная роль и первенствующее значение в государственной жизни» [13. С. 87; 22. С. 174-178]. Подобный подход был отражен и в программе Царско-народного русского общества (ЦНРО), действовавшего в Казани и Казанской губернии. В ней заявлялось, что русской национальности, собравшей Русское государство, «должна принадлежать первенствующая роль в государственном строительстве» [13. С. 55].

Вместе с тем поволжские традиционалисты, как и общероссийские, в национально-территориальном пространстве России разделяли коренные русские земли, к которым причислялось и Поволжье, и национальные окраины. Под окраинами подразумевались те регионы России, которые «вошли в состав государства сравнительно недавно», и они рассматривались не как собранные племена и земли, а как «народности, присоединенные к нам вследствие утраты ими своей политической самостоятельности или уничтожения их в связи с соседними нам государствами» [13. С. 57]. 
Из такой дифференциации вытекало и отношение поволжских правых к нерусским народностям внутренней России и ее окраинной части. Это проявилось также в том, что правые Поволжья принципиальные основы национальной политики государства по отношению к «коренным» нерусским народностям и инородцам национальных окраин в своих программных положениях рассматривали обособленно. ЦНРО свои позиции относительно тех народностей, которые оно причисляло к «коренным», «исконным», выразило в разделе «Русская национальность и самобытность». Основы национальной политики в отношении народов национальных окраин России отразило в разделе «Окраины». Относительно первых в программе Общества говорилось: «Что касается других племен нашего Отечества, то в отношении их обязанность государства состоит в охранении всех их интересов, не противоречащих общему строю, и в содействии развитию и совершенствованию их национальных особенностей, поскольку они не вредят интересам общегосударственным, а также в обеспечении благоприятных условий для их хозяйственного и культурного развития, сообразно их желаниями» [13. С. 55]. С ним солидаризировалось ОЦСПП. «В отношении иноплеменных частей населения России, - подчеркивалось в его программной платформе, - обязанность государства оберегать их законные интересы и содействовать их хозяйственному и культурному развитию» [13. С. 87].

Следует подчеркнуть, что правомонархические партии не являлись «махровыми» националистами, как пытались представить их в советской историографии. Именно этот фрактор - сопричастность к общегосударственной жизни и общенациональным интересам России - являлся определяющим индикатором по отношению к нерусским народностям. Правые не обособляли от русских те народы в составе России, которые исторически доказали верность общенациональным интересам, которые сами считали себя «русскими». С одной стороны, поддерживая лозунг центральных правых «Россия для русских», региональная Астраханская народно-монархическая партия, тем не менее, скорректировала свое видение этого принципа. Газета «Русская правда», партийный орган АНМП, писала: «Русскому народу - действительное главенство в Империи, им созданной, ибо: «Россия для русских». Инородцам, вошедшим в великую семью русского народа с «собственной землей», - равенство гражданских прав и сохранение особенностей, не посягающих на единство и целость Российской Державы» [11. С. 644]. В программе ЦНРО содержались положения об уважении культуры, религии, устоев нерусских народов. Более того, в отличие от столичных правых консерваторов, заявлявших о необходимости использования на местах, в том числе на окраинах России, в качестве государственного языка только русского, и отводивших национальному языку только области семьи, литературы и церкви [14. Т. 1. С. 328] ${ }^{1}$, поволжские правые допускали употребление местного языка наряду с русским в органах суда и управления. «На окраинах должно быть введено, - отмечалось в программном положении Царско-народного русского общества, - такое же как и во всей России местное земское и городское самоуправление с дозволением употребления местных языков параллельно с государственным языком русских» [13. С. 57-58].

1 Это положение было отражено в постановлении IV Всероссийского съезда объединенного русского народа в Москве весной 1907 г. 
О необходимости обеспечения «равенства всех русских подданных перед законом» говорила Астраханская народно-монархическая партия. В контексте взаимосвязи национального вопроса с конфессиональным астраханские правые консерваторы заявляли о «свободе всех вероисповеданий, за исключением тех, которые противны нравственности и государственному порядку» [13. С. 38]. Исходя из подобной трактовки, АНМП допускала в членство в партии тех «верноподданных инородцев», которые разделяли взгляды партии. По этому поводу в прессе партия разъясняла, что правомонархисты «не делают различия между национальностями при условии, чтобы эти национальности были бы проникнуты братскими чувствами к русскому народу и жили бы с ним одной дружной семьей» [19; 10. С. 26].

Такие позиции правых в совокупности с традиционалистскими установками значительной части нерусского населения способствовали тому, что в Поволжье в числе местных отделов правых партий были чувашские отделы $[1,3]$. В 1908 г. в Казани было зарегистрировано Царско-народное мусульманское общество, насчитывавшее в губернии до 18 отделов с численностью более 240 человек [2]. В правых отделах, открытых Казанским Царско-народным обществом в Уфимской губернии, состояли и татары [9]. Последнему способствовало и то, что среди народностей неправославного вероисповедания правые особо выделяли мусульман. На этот счет в «Основоположениях СРН» 1906 г. отмечалось, что «Союз русского народа торжественно заявляет, что все нерусские народности, имеющие исконную племенную оседлость в коренной России и живущие извечно среди русского народа, он признает равными себе, своими верными и добрыми соседями, друзьями, сородичами, причем из иноверцев выражает свое благорасположение содержащим Магометов закон» [8. C. 307]. Об этом писала и казанская «Газета правых»: «По какому праву иноверцы осмеливаются писать законы русскому народу, который создал всю Российскую империю? Если это право и может быть признано, то только за теми инородцами, которые давно себя зарекомендовали верными Державе Русской - таковы трудолюбивые и честные татары Поволжья и многие православные приволжские инородцы» [4; 12. С. 129].

Первая мировая война обострила национальный вопрос. Наряду с польским и кавказским вопросом, продолжающимися требованиями Финляндией автономии, актуализировалась и немецкая проблематика. В новых условиях взгляды правых в национальном вопросе подверглись определенной корректировке в сторону радикализации, что особо касалось именно окраинной части империи. В частности, председатель АНМП Н.Н. Тиханович-Савицкий, касаясь вопроса создания союза польского коло с кадетами в Государственной Думе, заявлял, что «русскому народу... не нужны в качестве законодателей люди, ... отдающие 18 млн русских в Западном крае во власть ничтожной горсточки пришельцевполяков» [6. Л. 121]. В «Основных положениях народных монархических союзов», предложенных этой партией в 1916 г. (деятельность остальных поволжских правых партий к этому времени практически сошла на нет), говорилось о том, что покоренные или добровольно вошедшие в состав Российского государства народы «пользуются одинаковыми правами с русским народом», если «живут с ним одними помыслами и интересами» и не будут представлять опасности его национальным интересам. С другой стороны, в эти же «Основные положения...» была включена статья, ограничивавшая численность нерусских народов «одной третью всего населения русского». В случае роста численности нерусского населения вследствие различных фракторов предлагалось выделить «излишек в ав- 
тономные области под властию государства Российского» или признать «владениями колониальными» [14. Т. 2. С. 555].

Таким образом, национальный вопрос в программатике правых консерваторов исходил прежде всего из приоритета общеимперских интересов над узконациональными. Базовыми принципами выступали традиционалистские ценности, единство народов страны и неделимость государства. Вместе с тем в ней учитывались особенности многонациональных и поликонфессиональных регионов, что и отразилось в специфике национальной проблематики в воззрениях правых партий и организаций Поволжья.

\section{Литература}

1. Алексеев И.Е. Русское национальное движение в Казанской губернии и Татарстане: конец XIX - начало XXI веков (опыт словаря). Казань: Мастер Лайн, 2004. 322 с.

2. Алексеев И.Е. Татарский след в черносотенном движении [Электронный реcypc]. URL: http://www.rusk.ru/st.php?idar=104032 (дата обращения: 15.10.2020).

3. Алексеев И.E. Чуваши-черносотенцы [Электронный ресурc]. URL: http:/ /www.rusk.ru/st.php?idar=110487 (дата обращения: 21.10.2020 г.).

4. Газета правых. 1906. № 1.

5. Государственный архив Астраханской области. Ф. 745. Оп. 1. Д. 1.

6. Государственный архив Российской Федерации. Ф. 102. 4 д-во. 1915. Д. 110.

7. Иванов А.А. Вызов национализма: Лозунг «Россия для русских» в дореволюционной общественной мысли. СПб.: Владимир Даль, 2016. 511 с.

8. Кирьянов Ю.И. Правые партии в России. 1911-1917. М.: РОССПЭН, 2001. 464 с.

9. Максимов К.В. Мусульмане в монархическом движении Уфимской губернии начала XX в [Электронный ресурc]. URL: https://rusk.ru/st.php?idar=102664 (дата обращения: 20.10.2020).

10. Михайлова Е.М. Идеология правых партий и организаций Поволжья начала XX в. (региональный аспект) // Вопросы истории. 2007. № 11. С. 18-34.

11. Михайлова E.M. «Монархия должна быть самодержавна по форме и демократичная по своим задачам...» Нестор Николаевич Тиханович-Савицкий (1866 - после июля 1917) // Правая Россия. Жизнеописания русских монархистов начала XX века / сост. А.А. Иванов, А.Д. Степанов. СПб.: Царское дело; Русская народная линия, 2015. 736 с.

12. Михайлова Е.М. Правомонархическое движение в Поволжье в 1905-1917 годах // Отечественная история. 2007. № 1. С. 126-134.

13. Михайлова Е.M. Правые партии и организации в Поволжье: идеологические концепции и организационное устройство (1905-1917). М.: МИРОС, 2002. 203 с.

14. Правые партии. 1905-1917. Документы и материалы: в 2 т. М.: РОССПЭН, 1998.

15. Размолодин М.Л. О консервативной сущности черной сотни. 2-е изд., доп. и перераб. Ярославль: Нюанс, 2012. 388 с.

16. Размолодин М.Л. Русский вопрос в идеологии черной сотни. 2-е изд., доп. и перераб. Ярославль: Нюанс, 2013. 480 с.

17. Репников А.В. Консервативные концепции переустройства России. М.: Academia, 2007. $520 \mathrm{c}$.

18. Российский государственный исторический архив (РГИА). Ф. 1284. Оп. 187. Г. 1906. Д. 43.

19. Русская правда. 1907. 11 янв.

20. Русское знамя. 1907. 22 июля.

21. Устав и основоположения Союза русского народа. М., 1906.

22. Циунчук Р.А. Думская модель парламентаризма в Российской империи: этноконфессиональное и региональное измерения. Казань: ФЭН, 2004. 416 с.

МИХАЙЛОВА ЕЛИЗАВЕТА МИХАЙЛОВНА - ДОкТор историческиХ наук, професcop, заведующий кафедрой гуманитарных дисциплин и иностранных языков, Чебоксарский кооперативный институт (филиал) Российского университета кооперации, Россия, Чебоксары (lizamem@yandex.ru; ORCID: https://orcid.org/0000-0002-60359571). 


\title{
Elizaveta M. MIKHAILOVA \\ NATIONAL ISSUE IN THE POLITICAL IDEOLOGY OF RIGHT-WING CONSERVATISM: IMPERIAL AND REGIONAL DISCOURSE
}

\author{
Key words: national issue, right-wing parties, right conservatism, imperial \\ model, the Volga region, beginning of the $20^{\text {th }}$ century.
}

\begin{abstract}
The article analyzes the views of right-wing-conservative parties and organizations of the beginning of the $20^{\text {th }}$ century on the national issue. The positions of the right wingers in relation to the Russian people, non-Russian nationalities of inner Russia and the nationalities of national fringes are examined; factors of such differentiation are identified. Particular attention is paid to the peculiarities of the national policy carried on by the right-wing conservative parties and organizations of the Volga region dictated by the multinational and multiconfessional composition of the region. The author singles out positions similar to the All-Russian right-wing parties among the Volga conservatives, in particular in defending the principle of unity and indivisibility of the Russian Empire, preventing dismemberment of the country. The distinctive features of the national issues in the right monarchical parties of the Volga region were determined, they were expressed in the fact that their program platforms included provisions on granting foreigners civil rights which were equal to the ones given to the Russians, on admitting the right to believe in the faith of one's choice to the non-Orthodox, on using national languages in parallel with the state Russian language. The factors of radicalization among right-wing conservatives of national themes in the conditions of the First World War were noted.
\end{abstract}

\section{References}

1. Alekseev I.E. Russkoe natsional'noe dvizhenie $v$ Kazanskoi gubernii $i$ Tatarstane: konets XIX - nachalo XXI vekov (opyt slovarya) [Russian national movement in the Kazan province and Tatarstan at the end of the $19^{\text {th }}$ and early $20^{\text {th }}$ centuries (dictionary experiment)]. Kazan, Master Lain Publ., 2004, 322 p.

2. Alekseev I.E. Tatarskii sled $v$ chernosotennom dvizhenii [Tatar participation in the Black Hundred movement]// Available at: http://www.rusk.ru/st.php?idar=104032 (Accessed 2020, Oct. 15).

3. Alekseev I.E. Chuvashi-chernosotentsy [Chuvash members of the Black Hundred]. Available at: http://www.rusk.ru/st.php?idar=110487 (Accessed 2020, Oct. 21).

4. Gazeta pravykh, 1906, no. 1.

5. Gosudarstvennyi arkhiv Astrakhanskoi oblasti. F. 745. Op. 1. D. 1 [State Archives of the Astrakhan Region. Archive 745. Anagraph 1. Document 1].

6. Gosudarstvennyi arkhiv Rossiiskoi Federatsii. F. 102. 4 d-vo. 1915. D. 110 [State Archives of the Russian Federation. Archive 102].

7. Ivanov A.A. Vyzov natsionalizma: Lozung «Rossiya dlya russkikh» $v$ dorevolyutsionnoi obshchestvennoi mysli [Nationalist challenge: the "Russia is for the Russians" motto in the pre-revolutionary national thought]. St. Petersburg, Vladimir Dal Publ., 2016, 511 p.

8. Kir'yanov Yu.I. Pravye partii v Rossii. 1911-1917 [Right-wing parties in Russia. 1911-1917]. Moscow, ROSSPEN Publ., 2001, 464 p.

9. Maksimov K.V. Musul'mane $v$ monarkhicheskom dvizhenii Ufimskoi gubernii nachala $X X v$ [Muslims in the monarchist movement in the Ufa province at the beginning of the $20^{\text {th }}$ century]. Available at: https://rusk.ru/ st.php?idar=102664 (Accessed 2020, Oct. 20).

10. Mikhailova E.M. Ideologiya pravykh partii i organizatsii Povolzh'ya nachala XX v. (regional'nyi aspekt) [Ideology of right-wing parties and organizations of the Volga region at the beginning of the $20^{\text {th }}$ century (regional aspect)]. Voprosy istorii, 2007, no. 11, pp. 18-34.

11. Mikhailova E.M. "Monarkhiya dolzhna byt' samoderzhavna po forme $i$ demokratichnaya po svoim zadacham...» Nestor Nikolaevich Tikhanovich-Savitskii (1866 - posle iyulya 1917) ["Monarchy must be autocratic in its form and democratic in its objectives» Nestor Nikolaevich Tikhanovich-Savitskii (1866 - after July 1917)]. In: Ivanov A.A., Stepanov 
A.D., comp. Pravaya Rossiya. Zhizneopisaniya russkikh monarkhistov nachala $X X$ veka [Right-wing Russia. Biographies of Russain monarchists of the early $20^{\text {th }}$ century]. St. Petersburg, 2015, $736 \mathrm{p}$.

12. Mikhailova E.M. Pravomonarkhicheskoe dvizhenie v Povolzh'e v 1905-1917 godakh [Right-wing monarchist movement in the Volga region in 1905-1917]. Otechestvennaya istoriya, 2007 , no. 1 , pp. 126-134.

13. Mikhailova E.M. Pravye partii i organizatsii v Povolzh'e: ideologicheskie kontseptsii $i$ organizatsionnoe ustroistvo (1905-1917) [Right-wing parties and organizations in the Volga region: narratives and organizational set-up (1905-1917)]. Moscow, MIROS Publ., 2002, 203 p.

14. Pravye partii. 1905-1917. Dokumenty i materialy: v $2 t$ [Right-wing parties. 19051917. Documents and materials. 2 vols]. Moscow, ROSSPEN Publ., 1998.

15. Razmolodin M.L. O konservativnoi sushchnosti chernoi sotni. 2-e izd [On the conservative nature of the Black Hundred. $2^{\text {nd }}$ ed.]. Yaroslavl, Nyuans Publ., 2012, 388 p.

16. Razmolodin M.L. Russkii vopros $v$ ideologii chernoi sotni. 2-e izd [The Russian question in the ideology of the Black Hundred. $2^{\text {nd }}$ ed.]. Yaroslavl, Nyuans Publ., 2013, 480 p.

17. Repnikov A.V. Konservativnye kontseptsii pereustroistva Rossii [Conservative concepts of rebuilding Russia]. Moscow, Academia Publ., 2007, 520 p.

18. Rossiiskii gosudarstvennyi istoricheskii arkhiv. F. 1284. Op. 187. G. 1906. D. 43 [Russian State Historical Archive. Archive 1284. Anagraph 187. Document 43].

19. Russkaya pravda, 1907, Jan. 11.

20. Russkoe znamya, 1907, July 22.

21. Ustav i osnovopolozheniya Soyuza russkogo naroda [Memorandum and fundamental principles of the Union of the Russian people]. Moscow, 1906.

22. Tsiunchuk R.A. Dumskaya model' parlamentarizma $v$ Rossiiskoi imperii: etnokonfessional'noe i regional'noe izmereniya [The State Duma's parliamentary system model in the Russian Empire: ethnic-confessional and regional dimensions]. Kazan, FEN Publ., 2004, 416 p.

ELIZAVETA M. MIKHAILOVA - Doctor of Historical Sciences, Professor, Head of Department of Humanities and Foreign Languages, Cheboksary Cooperative Institute (Branch) the Russian University of Cooperation, Russia, Cheboksary (lizamem@yandex.ru; ORCID: https://orcid.org/0000-0002-6035-9571).

Формат цитирования: Михайлова Е.М. Национальный вопрос в политической идеологии правого консерватизма: имперский и региональный дискурс // Исторический поиск. - 2020. - Т. 1, № 4. - С. 69-76. DOI: 10.47026/2712-9454-2020-1-4-69-76. 